\title{
MONOLINGUAL AND BILINGUAL COMMUNICATION BETWEEN PATIENTS WITH DEMENTIA DISEASES AND THEIR CAREGIVERS
}

\section{AKADEMISK AVHANDLING}

som med vederbörligt tillstånd av Rektorsämbetet vid Umeå Universitet för avläggande av doktorsexamen i medicinsk vetenskap kommer att offentligen försvaras i Humanisthusets hörsal G, Umeå Universitet, fredagen den 28 maj $1993 \mathrm{kl} 09.00$

av

Sirkka-Liisa Ekman

Umeå 1993 


\section{UMEÅ UNIVERSITY MEDICAL DISSERTATIONS New Series No 370 - ISSN 0346-6612 ISBN 91-7174-785-0}

\section{Monolingual and bilingual communication between patients with dementia diseases and their caregivers}

Sirkka-Liisa Ekman, Department of Advanced Nursing, Umeå University, Department of Geriatric Medicine, the Karolinska Institute, Stockholm, Sweden

\section{ABSTRACT}

The purpose of the thesis was to elucidate demented monolingual patients' communicative behaviour as described by their caregivers, and demented bilingual patients' communication, interaction, and relationship with caregivers who could/could not Finnish.

The first part of the thesis includes two time-studies and interviews with caregivers in the geriatric care of monolingual patients (I, II). The caregivers spent less time caring for the demented patients than for the non-demented patients with the same degree of dependence. The problems to communicate with the demented patients caused ethical problems and jeopardized the caregivers' commitment.

In the second part of the thesis the preconditions for communication were studied by means of medical, neuropsychological, and linguistic examination of demented Finnish immigrants. Patients' relatives were interviewed and patients' interaction with caregivers was observed in standardised situations (III). The communication, interaction, and relationship between bilingual demented patients and mono/bilingual caregivers were studied during video-recorded morning care sessions by the E.H. and J. Erikson theory of 'eight stages of man'. Phenomenological-hermeneutic (IV), and factor analysis (V) was performed. Also phenomenological (VI) analysis of the morning care sessions was used. The patients functioned on a higher level of ability together with the bilingual caregivers. These caregivers promoted the patients' integrity in a more comprehensive way than monolingual caregivers, and the patients exhibited more trust, autonomy, initiative, industry, identity, intimacy, generativity, and integrity. Their interaction with bilingual caregivers was more multidimensional and the progression of their interaction was more positive than that with monolingual caregivers. The bilingual caregivers' relationship with the demented immigrants was characterised by communion; disclosure of virtues such as patience, honesty, and humility; respect for the person; will; and joy.

The findings of the study are discussed within a hermeneutic-humanistic perspective stressing the patient's dependence, vulnerability and need for support. The conclusion is that verbal communication in the patients' native language makes it easier for caregivers to promote patients' integrity, which in turn enables patients to disclose more of their latent capacity.

Key words: Dementia, bilingual, immigrant, communication, interaction, relationship, E. H. Erikson's theory, phenomenological-hermeneutics, phenomenology. 


\section{UMEÅ UNIVERSITY MEDICAL DISSERTATIONS \\ New Series No 370 - ISSN 0346-6612}

From the Department of Advanced Nursing, Umeå University, and the Department of Geriatric Medicine, the Karolinska Institute, Stockholm, Sweden

\section{MONOLINGUAL AND BILINGUAL COMMUNICATION BETWEEN PATIENTS WITH DEMENTIA DISEASES AND THEIR CAREGIVERS}

\section{Sirkka-Liisa Ekman}

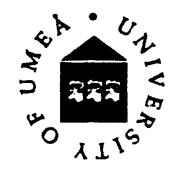

Umeå 1993 
Copyright (C 1993 by Sirkka-Liisa Ekman ISBN 91-7174-785-0

Printed in Sweden by Solfjädern Offset $A B$ Umeå 1993 
To all elderly Finns in Sweden 
'I believe

The greatest gift

I can conceive of having

from anyone

is

to be seen by them, heard by them, to be understood and touched by them. The greatest gift I can give is

to see, hear, understand and to touch another person. When this is done I feel contact has been made'.

Virginia Satir (1976) 


\section{CONTENTS}

ABSTRACT

ORIGINAL PAPERS $\quad 8$

INTRODUCTION 9

The dementia syndrome 9

Care of patients with dementia diseases $\quad 10$

Communication in the care of patients 10

Migration 11

Bilingualism $\quad 14$

Bilingualism and dementia $\quad 14$

AIM 15

METHODS $\quad 15$

The choice of methods $\quad 15$

The design of the studies $\quad 15$

Patients 16

$\begin{array}{ll}\text { Caregivers } & 17\end{array}$

$\begin{array}{ll}\text { Methods } & 19\end{array}$

Theoretical framework 23

The Erikson theory applied to the demented patient 25

Analyses of the video-recorded morning care sessions 26

The author's pre-understanding 28

The ethical considerations $\quad 28$

RESULTS 29

Time-studies $\quad 29$

Caregiver interviews $\quad 29$

Preconditions for the patients' communication $\quad 30$

Relationship between demented patients and their monolingual and bilingual caregivers 


\section{DISCUSSION}

Critique of the methods used in the study

The demented patients' preconditions for communication

Interpretations of the consequence of migration in the light of the Erikson theory

Care of the demented monolingual and bilingual patients $\quad 38$

Interpretation of the findings seen as a whole

ACKNOWLEDGEMENTS

REFERENCES

Paper I

Paper II

Paper III

Paper IV

Paper V

Paper VI

Information about the Dissertations from the Department of Advanced Nursing, Umeå University

Information about the Dissertations from the Department of Geriatric Medicine, Karolinska Institute 
Monolingual and bilingual communication between patients with dementia diseases and their caregivers.

Sirkka-Liisa Ekman, Department of Advanced Nursing, University of Umeå, and Department of Geriatric Medicine, the Karolinska Institute, Stockholm, Sweden

\section{ABSTRACT}

The purpose of the thesis was to elucidate demented monolingual patients' communicative behaviour as described by their caregivers, and demented bilingual patients' communication, interaction, and relationship with caregivers who could/could not speak Finnish.

The first part of the thesis includes two time-studies and interviews with caregivers in the geriatric care of monolingual patients (I, II). The caregivers spent less time caring for the demented patients than for the non-demented patients with the same degree of dependence. The problems to communicate with the demented patients caused ethical problems and jeopardized the caregivers' commitment.

In the second part of the thesis the preconditions for communication were studied by means of medical, and neuropsychological, examination of demented Finnish immigrants. Patients' relatives were interviewed and patients' interaction with caregivers was observed in standardised situations (III). The communication, interaction, and relationship between bilingual demented patients and mono/bilingual caregivers were studied during video-recorded morning care sessions by the E.H. and J. Erikson theory of 'eight stages of man'. Phenomenological-hermeneutic (IV), and factor analyses (V) were performed. Also phenomenological (VI) analysis of the morning care sessions was used. The patients functioned on a higher level of ability together with the bilingual caregivers. These caregivers promoted the patients' integrity in a more comprehensive way than monolingual caregivers, and the patients exhibited more trust, autonomy, initiative, industry, identity, intimacy, generativity, and integrity. Their interaction with bilingual caregivers was more multidimensional and the progression of their interaction was more positive than that with monolingual caregivers. The bilingual caregivers' relationship with the demented immigrants was characterised by communion; disclosure of virtues such as patience, honesty, and humility; respect for the person; will; and joy.

The findings of the study are discussed within a phenomenologicalhermeneutic perspective emphasizing the patient's dependence, vulnerability and need for support. The conclusion is that verbal communication in the patients' native language makes it easier for caregivers to promote patients' integrity, which in turn enables patients to disclose more of their latent capacity.

Key words: Dementia, bilingual, immigrant, communication, interaction, relationship, E. H. Erikson's theory, phenomenological-hermeneutics, phenomenology. 


\section{ORIGINAL PAPERS}

This thesis is based on the following studies, which will be referred to in the text by their Roman numerals:

1 Ekman, S-L , Norberg, A., Viitanen, M., \& Winblad, B. Care of demented patients with severe problems of communication. Timestudies and interviews with caregivers. Scandinavian Journal of Caring Sciences, 5, 163-170, 1991.

2 Ekman, S-L., \& Norberg A. The autonomy of demented patients: interviews with caregivers. Journal of Medical Ethics, 14, 184-187, 1988.

3 Ekman, S-L., Robins Wahlin, T-B., Viitanen, M., Norberg, A.,\& Winblad, B. Preconditions for communication in the care of bilingual demented persons. International Psychogeriatrics, in press.

4 Ekman, S-L., Robins Wahlin, T-B., Norberg, A., \& Winblad, B. Relationship between bilingual demented immigrants and bilingual/monolingual caregivers. International Journal of Aging and Human Development, 37, 37-54,1993.

5 Ekman, S-L., Norberg, A., Robins Wahlin, T-B., \& Winblad B. Dimensions and progression in the interaction between bilingual/monolingual caregivers and bilingual demented immigrants. Analysis of video-recorded morning care sessions in institutions coded by means of the Erikson theory of 'eight stages of man'. Submitted for publication.

6 Ekman, S-L. \& Norberg, A. Characteristics of the good relationship in the care of demented bilingual immigrants. Submitted for publication.

The papers are reprinted with the kind permission of the respective journal. 


\section{INTRODUCTION}

\section{The dementia syndrome}

Dementia is often defined according to the Diagnostic and Statistical Manual of Mental Disorders, 3rd edition, revised, (DSM III-R) published by the American Psychiatric Association (APA) (1987 pp. 97-163). According to this definition, dementia is characterized by memory impairment and some other cognitive and/or personality deficits sufficiently large to interfere with social life or work without any disturbance of consciousness. Dementia diseases can be divided into three groups: primary degenerative dementia, vascular dementia, and secondary dementia. Alzheimer's disease.

The most common dementia disease is Alzheimer's disease (AD) (nearly $50 \%$ of all dementia cases) and the second most common disease is vascular dementia (VD). Sometimes the patient suffers from both (mixed AD and VD) (Erkinjuntti 1988). The clinical diagnosis of Alzheimer's disease is mostly made according to the DSM III-R criteria or NINCDS-ADRDA criteria (McKhann et al. 1984). Common methods used to estimate the level of the dementia disease are the Mini Mental State Examination (MMSE) (Folstein et al. 1975) and the Global Deterioration Scale (GDS) (Reisberg 1983, Reisberg et al. 1989). Family members' narratives about patients' symptoms and actions in everyday life, and in their own social milieu, are important information when making the clinical diagnosis.

During the course of dementia there is gradual impairment in the communicative ability of the demented patients (Bayles \& Kaszniak 1987). Obler and Albert (1984) suggest that this deterioration is regular in people suffering from AD. Hyltenstam and Stroud (1989) have described this regression in three stages; early, middle and late stages. In the early stage, lexical search difficulties prevail, but the patient may also make unmotivated conversational digressions and give inadequate answers to questions. At this level, the patients are aware of their communicative problems. In the middle stage, the difficulties on the semantic and pragmatic levels increase. Severe digressions and so called "empty speech" are typical. Some difficulties in producing automatic speech appear. Phonology, morphology and syntax seem to be largely intact. In this stage the patients show no cues that indicate that they are aware of 
their language problems. In the late stage, limited linguistic resources remain. Echolalia and mutism are characteristic features of this stage (Obler \& Albert 1984, Reisberg et al. 1989). Some demented patients exhibit vocally disruptive behaviour, such as shouting or screaming (Hallberg et al. 1993).

The severely demented also have problems in their non-verbal communication. Their facial expressions (Norberg et al. 1986, Asplund et al. 1991b, Jansson et al. 1993) and gestures (Critchley 1964) are less expressive than those of healthy elderly people and they have difficulties to read the cues in another person's face (Kurucz \& Feldmar 1979).

Communication problems are not connected only to language but also to symptoms such as amnesia (Miller 1989, Abeysinghe et al. 1990), apraxia (Della Sala et al. 1987, Rapcsak et at. 1989), agnosia (Broderick \& Laszlo 1987, Miller 1989) and the decline in logical reasoning (Lewis \& Livson 1980).

\section{Care of patients with dementia diseases}

Communication problems lead to difficulties in the care of demented patients. Kihlgren (1992) has shown that it is in fact possible to influence the care of the demented patients positively by training caregivers in supporting patients' experience of integrity (wholeness and meaning). Problems to interpret the demented patient's communicative cues lead to the ethical problems in care (Kuuppelomäki \& Lauri 1991, Jansson \& Norberg 1992).

Being able to communicate with patients is important to the caregivers' own experience of meaning in the care of the demented (Hallberg \& Norberg 1990, Norberg \& Asplund 1990, Åkerlund \& Norberg 1990). Asplund (1991 pp. 25-35) suggests that there is a connection between caregivers' possibilities to communicate with their patients and their own philosophy of life. Caregivers regarding life as a gift and an ethical demand accept demented patients more easily and find it meaningful to take care of them.

\section{Communication in the care of patients}

The relationship between patient and caregiver is an important aspect of caring. The interaction between the parties is the basis of their 
relationship. The interaction is made possible by means of communication, which is a very complicated event with many different aspects, from perception to practice ( $c f$. Ringler 1983). Watzlawick and co-workers (1967 pp. 48-51) have formed some axioms about human communication, the first is: 'one cannot not communicate'. Activity or passivity, words or silence always disclose something. We communicate on the level of the content of the message and on the level of the relationship between the communicating persons (meta-communication). The non-verbal communication reinforces the verbal message but it sometimes has an opposite meaning, causing confusion in the receiver.

A human being's language development starts very early. Babies have intensive interaction with their caregivers (Merleau-Ponty 1973, Ringler 1983, Stern 1990). As early as during the first few months they can recognize the rhythm of their mothers' language and they 'babble' adequately to communicate in their interaction (Ringler 1983). The rhythm of the language varies in different cultures (Condon 1980, Kempton 1980). Kempton (1980) states that a comparison between communication and dance is relevant. The interactants must both know the rhythm to bring synchrony into their communication.

Communication is mutual and simultaneous and influences people; it is not a system flowing from one person to another. It is a fundamental part of people's existence and therefore it cannot be studied outside its 'involvement', i.e. what it means and does to the communicating parties (Condon 1980). Condon (1980) states that communication is not only a process of content messages between people but it is also an 'overarching domain' of trust and mistrust, love and hate, acceptance or rejection of oneself and others. The parties meet in the interaction as individuals with their own history and future (Norberg et al. 1992).

\section{Migration}

Throughout time all over the world there has been some kind of migration. Often people leave their home countries in the hope of finding a better future, for example, better employment opportunities and a better economic situation. For some people the love of adventure makes them emigrate. In this day and age with social and political unrest in many parts of the world the stream of refugees has become a reality. The refugees have been forced to leave their home countries in contrast to the 
immigrants who left of their own free will. These groups may experience migration differently but in many situations later in life they have the same problems in adaptating to their new countries.

Migration means not only outer environmental changes but also balancing of inner values and beliefs both in the new and the old countries. These people do not only build up new social networks; they also try hard to preserve their old networks in order to secure some continuity in their lives ( $c f$. Schierup 1987). Continuity is needed for people's development of identity (Erikson 1974, 1982). Erikson (1974) points to the importance of being one with one's own future as well as with one's own history for the positive development of a sense of new identity after migration. This is in agreement with descriptions of migration as a dynamic process involving factors of the past, e.g. values and beliefs from the home country, as well as factors of the future, e.g. the values of the new country (Alund 1978, 1985). It is very hard, perhaps impossible, to adapt fully to another culture in an absolute sense (Lewis \& Jungman 1986 pp. 207). It is important for immigrants to gain acceptance regarding their 'bicultural identity' to be able to develop.

Very limited research has been found concerning how old people belonging to an ethnic minority group may experience their situation. The lack of research in this area has meant poor theoretical discussion, which, in turn, results in poorly conceptualized research (Markides \& Mindel 1987, p. 44).

\section{Migration from Finland to Sweden}

Nearly 600000 people emigrated from Finland between 1946 and 1979 (Majava 1981 pp. 232). An overwhelming part of this migration (about 440000 people) has gone to Sweden (Koivukangas 1980). Until 1955 there was an excess of female emigrants, who were very young (1830 years old) (Majava $1981 \mathrm{pp} 232$ ). The majority of the adult emigrants were unmarried.

The Finnish immigrants in Sweden have married to the same degree as Swedish people (Majava 1981 pp. 237). The share of divorced Finnish people has been about three times higher than among the Finns in Finland and about twice as high as among Swedish people in Sweden. The difficulties of migration might be a reason for this breaking up of marriages. 
An overwhelming majority of the Finnish immigrants has lived in urban areas in Sweden, though most of them had a rural background in their home country. Most of these people moved to Sweden in the hope of finding better employment opportunities. Both the Finnish men and women in Sweden run much more risk of being unemployed than the native population (Majava 1981 pp. 243). Metal work, manufacturing, and service work were the most common jobs among the Finnish immigrants.

During the 1946-1975 period over 50 per cent of the Finnish immigrants lived in rented apartments while the majority of the Swedes, as well as the Finns in Finland, owned their own homes (Majava 1981 pp. 247). They were also much less involved in union activities (and political activities) in their social environment. Their social networks were smaller than those of the Swedes, or those of the Finns in Finland (Jaakkola 1983). They had very few social contacts with Swedes; isolation was a major problem in their lives. The main reason for the lack of contact with Swedes was probably their poor ability to speak Swedish. In the 1946-1975 period (before the new Swedish migration policy took effect) there was no organized education in Swedish for immigrants. The only possibility was to learn it in one's spare time, but hard work and adaptation problems made this very difficult. Also their motivation may have been poor because of their plans to soon return to Finland before long. The situation described has probably changed in some aspects, but these preconditions were common during the time when the people, who are 65 years and older today, had their most active period.

In Sweden 23000 Finnish immigrants who were 65 years old or older have been registered (National Board of Health and Welfare \& Swedish Immigration Board 1991). The calculated numbers for the same group in 2000 and 2010 are as high as 54000 and 64000 with the same immigration and emigration frequency as in 1989. This high increase is connected with the migration of young people between 1940 and 1950 mentioned earlier. Most of the old Finnish immigrants have become Swedish citizens (Koivukangas 1980), which makes it difficult to single out these people in the ordinary statistics used for the planning of their service. With an estimated prevalence of 5\% dementia among people aged 65 years and above (Sandman et al. 1988), by the year 2010 there may be 3200 demented Finnish immigrants in Sweden. 


\section{Bilingualism}

Bilingualism is common all over the world. There are many countries with more than one official language and where people talk several languages. Another kind of situation is seen in the countries which are traditionally homogenous and have only one main language. After the large immigration or stream of refugees minority ethnic groups have developed and bilingualism has become a new aspect of the everyday life of a lot of people.

Young children (1-4 years old) can become bilingual without mixing the languages (Meisel 1989). It is, however, very difficult to learn the 'other' language 'perfectly' (Hyltenstam 1988). The acquisition of the second language is even more difficult in adulthood (Bolander 1989). People need a lot of motivation and frequent opportunities to use the second language. As they grow elder bilingual people undergo some changes regarding their use of the second language for example more interference problems in language mixing and language choice (Clyne 1977, 1987).

\section{Bilingualism and dementia}

Bilingual demented people have been poorly studied to date. Demented immigrants have the following kinds of language problems; - problems connected with the fact that they are bilingual and old; they are, for example, more likely to mix languages perhaps relating to retirement and fewer possibilities to interact socially

- problems common among patients with Alzheimer's disease, for example difficulties to find words, and to name objects

- the special problems seen in bilingual patients with Alzheimer's disease, for example problems with language choice and language separation.

Language choice is the process whereby a bilingual speaker selects the appropriate language according to situational cues such as the language status of the interlocutor (Grosjean 1982). The notion of language separation refers to the bilingual speaker's ability to keep her/his two languages apart in the verbal production. Inability in this respect leads to code-switching, which can be defined as a bilingual speaker's alternate use of two languages within the same discourse (Poplack 1980). Inappropriate language choice and involuntary code- 
switching seem to exist independently of each other in the demented (Hyltenstam \& Stroud 1989).

It seems logical to assume that bilingual language problems combined with the communication problems seen in monolingual demented patients result in severe communication problems in care, especially when caregivers do not speak and understand the native language of the demented patients. Communication problems might lead not only to too early or incorrect dementia diagnoses but also an inadequate judgement of the severity of the stage of the disease.

\section{AIM}

The aims of this study were to a) elucidate monolingual caregivers' use of time with monolingual demented/non-demented patients and their experience of the care of severely demented patients b) describe demented bilingual patients' communicative behaviour together with caregivers who knew/did not know the demented patients' native language, c) elucidate the interaction between bilingual demented patients and their monolingual/bilingual caregivers and to d) illuminate the quality of the relationship between demented Finnish immigrants and their monolingual/bilingual caregivers.

\section{METHOD}

\section{The choice of methods}

When this study was planned a system theoretical and a behavioural framework of communication was used. But during the course of the study the theoretical frame has been changed to a more phenomenological-hermeneutical one, with more emphasis on the importance of the preverbal meaning of language in the interaction between patient and caregiver in order to support a good relationship between them.

\section{The design of the studies}

The studies consisted of two parts. The first part was performed with monolingual geriatric patients and their monolingual caregivers and the 
second part was performed with bilingual demented patients and their monolingual/bilingual caregivers.

\section{Part I.}

The first part of the study included two time studies and one interview study made in a geriatric clinic, in northern Sweden. The wards had demented patients as well as non-demented patients with various kinds of geriatric disorders. The interviews (I, II) were made at three of the wards of a clinic.

\section{Part II.}

The second part of the study was performed in the Greater Stockholm area, at nursing homes and geriatric clinics, with Finnish immigrants (III-VI)

\section{Patients}

\section{Part I.}

Caregivers were asked to choose a certain patient as reference when they talked about care situations and communication problems. The ADL performance and cognitive level of these patients were described using the Katz index (Katz \& Akpom 1976) and the Global Deterioration Scale (GDS) (Reisberg 1986) and can be seen in Table 1.

Table 1. Classifications of patients according to Katz-index and Global Deterioration Scale (GDS).

KATZ-index

\begin{tabular}{cccccccc} 
GDS & A & B & C & D & E & F & G \\
\hline $\mathbf{1}$ & & & & & & & \\
$\mathbf{2}$ & & & & & & & \\
$\mathbf{3}$ & & & & & & & \\
$\mathbf{4}$ & & & & & & & \\
$\mathbf{6}$ & & & & 1 & 2 & 3 & 9 \\
$\mathbf{7}$ & & & & & 1 & 2 & 3 \\
\hline
\end{tabular}

\section{Part II.}

The following criteria were set up for the patients participating in part II of the study (III-VI); demented who were born in Finland and who had immigrated to Sweden before the age of 50 and who had used 
both Finnish and Swedish regularly before the onset of dementia. Five hundred and sixty letters were sent to health care centres, nursing homes and geriatric hospitals in the Greater Stockholm area and the County Council of Västerbotten, Sweden. Physicians and head administrators were asked to report their demented Finnish immigrants.

Twenty patients were found and investigated. Nine patients who had too poor verbal communication, or were not demented, were excluded from further investigation. Two demented patients chose not to participate. The nine remaining patients (all women) were 70-94 years old (median=83). Two patients died during the period. The data missing and the characteristics of the patients are shown in Table 2 .

Table 2. Characteristics of patients

\begin{tabular}{cccccccc} 
Patient & $\begin{array}{c}\text { Age/Sex } \\
1988\end{array}$ & $\begin{array}{c}\text { Diagnosis } \\
1988\end{array}$ & $\begin{array}{c}\text { Duration } \\
\text { of disease } \\
1988\end{array}$ & $\begin{array}{c}\text { MMSE } \\
1988\end{array}$ & $\begin{array}{c}\text { GDS } \\
1988\end{array}$ & $\begin{array}{c}\text { MMSE } \\
1989\end{array}$ & $\begin{array}{c}\text { GDS } \\
1989\end{array}$ \\
\hline 1 & $86 / \mathrm{F}$ & AD & 5 & 6 & 6 & - & - \\
2 & $73 / \mathrm{F}$ & AD & 10 & 4 & 6 & 7 & 6 \\
3 & $73 / \mathrm{F}$ & AD & 5 & 6 & 6 & 6 & 6 \\
4 & $94 / \mathrm{F}$ & AD & 12 & 8 & 6 & - & - \\
5 & $73 / \mathrm{F}$ & AD & 10 & 13 & 5 & 16 & 5 \\
6 & $84 / \mathrm{F}$ & AD & 9 & 9 & 5 & 13 & 6 \\
7 & $70 / \mathrm{F}$ & VD & 5 & 1 & 6 & 3 & 7 \\
8 & $84 / \mathrm{F}$ & AD & 5 & 5 & 6 & 5 & 7 \\
9 & $83 / \mathrm{F}$ & AD/VD & 5 & 4 & 6 & 3 & 6 \\
\hline
\end{tabular}

$\mathrm{AD}=$ Alzheimer's Disease

$\mathrm{VD}=$ Vascular Dementia

\section{Caregivers}

\section{$\underline{\text { Part I }}$}

In the first step of time study No. 1 all registered nurses (RNs) at the clinic participated. In the second step all RNs, enrolled nurses (ENs), and nurses' aids at one of the wards participated. In time study No. 2 no caregiver took direct part.

In the interviews all ENs $(n=9)$ and nurses' aids $(n=15)$ who had worked for one to five (median $=2$ ) years at three of the five wards of the clinic, and who worked daytime during the three months of the interview, 
participated in the interviews (I, II). Three interviews were excluded due to technical problems. The remaining 21 interviewees consisted of nine ENs and twelve nurses' aids. The characteristics of the caregivers are shown in Table 3.

Table 3. Characteristics of caregivers of part I

\begin{tabular}{|c|c|c|c|c|}
\hline \multirow{2}{*}{$\begin{array}{l}\text { Professional } \\
\text { background }\end{array}$} & \multicolumn{2}{|c|}{ Sex } & \multirow{2}{*}{$\begin{array}{c}\text { Age (yrs) } \\
\text { Median (range) }\end{array}$} & \multirow{2}{*}{$\begin{array}{l}\text { Yrs in geriatric care } \\
\text { Median (range) }\end{array}$} \\
\hline & Female & Male & & \\
\hline EN & 8 & 1 & $28(21-49)$ & $1.5(1.2-4.1)$ \\
\hline Nurses' aid & 9 & 3 & $27(20-46)$ & $2.5(1.8-4.6)$ \\
\hline
\end{tabular}

\section{$\underline{\text { Part II }}$}

Sixteen caregivers participated in this study. Two of them interacted with all of the seven patients. One of them was bilingual and one monolingual. They had not met the patients before. The remaining 14 caregivers worked at the respective patient's ward, two caregivers for each patient, and they knew the patients quite well. Here too, one caregiver was bilingual and one monolingual. The characterics of the caregivers are shown in Table 4. 
Table 4. Characteristics of caregivers of part II

\begin{tabular}{|c|c|c|c|c|c|c|c|c|}
\hline \multirow{2}{*}{ NO } & \multicolumn{4}{|c|}{ Age/Sex (Female/Male) } & \multicolumn{3}{|c|}{ Profession } & \multirow{2}{*}{$\begin{array}{l}\text { Yrs in } \\
\text { dementia } \\
\text { care }\end{array}$} \\
\hline & $15-24$ & $25-34$ & $35-44 \quad 45-54$ & $55-64$ & RN & EN & Nurses' aid & \\
\hline 1 & & & $\mathrm{~F}$ & & $\mathrm{x}$ & & & 19 \\
\hline 2 & & & $\mathrm{~F}$ & & $\mathrm{x}$ & & & 21 \\
\hline 3 & $\mathrm{~F}$ & & & & & & $\mathrm{x}$ & 1.5 \\
\hline 4 & $\mathrm{~F}$ & & & & & & $\mathrm{x}$ & 5 \\
\hline 5 & $\mathrm{~F}$ & & & & & & $\mathrm{x}$ & 1 \\
\hline 6 & & $\mathrm{~F}$ & & & & $x$ & & 4.5 \\
\hline 7 & & & M & & & & $\mathrm{x}$ & 2 \\
\hline 8 & & $\mathrm{~F}$ & & & & $x$ & & 9 \\
\hline 9 & & & $\mathrm{~F}$ & & & & $\mathrm{x}$ & 5 \\
\hline 10 & & & & $\mathrm{~F}$ & & & $\mathrm{x}$ & 9 \\
\hline 11 & $\mathrm{~F}$ & & & & & & $\mathrm{x}$ & 3 \\
\hline 12 & & $\mathrm{~F}$ & & & & & $\mathrm{x}$ & 3 \\
\hline 13 & & $\mathrm{~F}$ & & & & $x$ & & 10 \\
\hline 14 & & & $\mathrm{~F}$ & & & $x$ & & 18 \\
\hline 15 & & & & F & & & $\mathrm{x}$ & 5 \\
\hline 16 & & & F & & & & $\mathrm{x}$ & 5 \\
\hline
\end{tabular}

\section{Methods}

Part I

The Katz' ADL index (Katz \& Akpom 1976) and the Global Deterioration Scale (GDS) (Reisberg 1986) were used to assess the symptoms and functional performance of the patients to diagnose the dementia (I).

Time studies were constructed by the author and one of the coauthors of paper I. Time study No. 1 was performed with all the RNs of the five wards and with all ENs and nurses' aids at one of the five wards of the same clinic (I). A self-rating method was used for economic reasons. The caregivers registered the time they used for their various tasks during one week, for example; basic care (food, hygiene, training), medical care (drugs, infusions, check-up), patient administration (phone contacts, nursing plans), personnel administration (supervision, instruction, supporting), information (reports, conferences, ward rounds), service (cleaning, kitchen work), and other tasks (waiting, breaks). During this registration no specific instructions were given to the 
personnel about how they should work. The total time registered for each member of the personnel was checked against the work schedule. The exact agreement was $95 \%$.

In the time-study No. 2 (I) a patient classification was made based on the patients' approximate need for basic nursing care which was estimated through discussions among the head physician, the RNs, the ENs and the nurses' aids caring for the patients. Five groups were formed. An observer (RN) assessed the patients belonging to these groups. All in all 20 assessments of eating and hygiene situations, respectively, in each of the groups were made.

A semi-structured interview with some discussion topics (Table 5) was made with nine ENs and twelve nurses' aids, who had worked daytime at this clinic for 1 to 5 years. They were asked to describe the differences between the care of demented patients and that of nondemented patients regarding morning care, evening care, toileting, and meals. The communication problems they had with their patients were also discussed. In order to make the interviews more concrete each interviewee was also asked to select a demented patient, whom she/he often took care of and describe the care situations and the communication patterns she/he had with this particular patient as well as what kind of reactions the communication difficulties caused in her/him. The interviews were tape-recorded and transcribed verbatim. A content analysis was made of the interview material which was regarded as a whole in order to obtain a sense of the content. Caregivers' accounts were listed according to the various topics and the lists were read and classified into themes and the patterns were then described (I). The interviews were also analysed regarding ethical principles as described by Beauchamp \& Childress (1983) (II). 
Table 5. Interview guide.

\section{General comparisons}

Differences in the way of caring for demented or non-demented patients.

How do they feel about it?

- Have they always felt like that?

- Do they feel like that about everybody?

Differences during morning care, evening care, toileting, meals.

Communication

*What does it mean to their work that it is difficult to communicate? *Do they usually go up to the patient just to talk?
Narrative about a certain patient

How do they find their work with these specific patients during morning care, evening care, toileting, and meals?

\section{Communication}

How is it possible to

communicate with this patient?

-How does his verbal communication function?

-How does his non-verbal communication function? -Is there any eye contact? -How does this patient react to music? -What about his territory?

-How does this patient react to body contact?

*Do they have some 'tricks' to make contact with demented patients? *How important is the patient's integrity?

*How important is the patient's autonomy?

\section{$\underline{\text { Part II }}$}

\section{Medical examination}

Medical records were collected from general practitioners and hospitals and the spouses or family members were interviewed to provide information on the medical history of the patient. Assessments used in studies on bilingual demented patients' neurological, psychiatric and somatic state were performed and laboratory data were collected from medical records. The diagnosis of AD was based on the DSM-III-R criteria (APA 1987). Depression was excluded by means of a subscale of the Comprehensive Psychopathological Rating Scale constructed by Montgomery and Åsberg (1979). The Hachinski Ischemic Score (Hachinski et al., 1975), the Mini Mental State Examination (MMSE) (Folstein et al., 1975), the Global Deterioration Scale (GDS) (Reisberg 
1986) and the Geriatric Rating Scale (GBS) (Gottfries et al., 1982) were also used (Table 2). The MMSE and the GDS examinations were performed in Finnish in 1988 and in 1989.

\section{Neuropsychological examination}

The neuropsychological examinations were performed one year after the other investigations, because of technical reasons. The investigation included visual perception, visuo-spatial orientation, expressive and impressive speech, motor function of hands (Christensen 1984); abstract thinking, visuo-spatial and constructive thinking (Wechsler 1981); visuomotor tracking (Reitan 1958); short term memory (Bäckman \& Karlsson 1986). The initial scoring criteria were taken from the WAIS-R scoring rules (Wechsler 1981) and from a study of the effects of normal aging (Laaksonen et al. 1985). These tests are commonly used and have proved valid both in Sweden and Finland (Erkinjuntti et al. 1986).

\section{Assessment of the demented patient's life story}

The demented patient's closest relative/friend was interviewed about the patient's life before and after the immigration. The semi-structured interviews were tape-recorded, transcribed verbatim, and analyzed theme by theme, comparing the life in Finland with that in Sweden. Comparisions between the life in Finland, and the life in Sweden, as well as before and after the patient had dementia, were made concerning education, job, family situation, network, interests, habits, personality, philosophy of life, important events, life situation after retirement, and description of her/his disease (III).

\section{Assessment of the communication in standardized situations}

The demented patients were given two concrete tasks to carry out together with a bilingual (Finnish-Swedish) as well as with a monolingual (Swedish) caregiver; 1) to wrap up two things with paper and string, 2) to read a magazine and discuss its content. In two cases no bilingual caregiver could be found at the respective ward/institution. Then the bilingual communication was assessed in interaction with the bilingual investigator. The demented patients' communicative ability during these standardized situations was analyzed from the tape-recordings by means of an analogous scale developed for this study (ranging from $0=$ no 
communication to 3 = adequate communication) independently by two investigators. The Pearson correlation coefficient was used to calculate inter-rater reliability, which was 0.92 (III).

Video-recorded morning care sessions

All seven patients were video-recorded during morning care together with; a) a bilingual caregiver who did not know them, b) a bilingual caregiver who knew them, c) a monolingual caregiver who did not know them, and d) a monolingual caregiver who knew them (Table 6).

Table 6. Design of video-recorded morning care sessions and patient-caregiver dyad number.

\begin{tabular}{|c|c|c|c|c|c|c|c|}
\hline $\begin{array}{l}\text { Caregiver } \\
\text { Bilingual= } F / S \\
\text { Monolingual }=S\end{array}$ & $\begin{array}{c}\text { Patient } \\
1 \\
\text { Dyad } \\
\text { No. }\end{array}$ & $\begin{array}{c}\text { Patient } \\
\mathbf{2} \\
\text { Dyad } \\
\text { No. }\end{array}$ & $\begin{array}{c}\text { Patient } \\
\mathbf{3} \\
\text { Dyad } \\
\text { No. }\end{array}$ & $\begin{array}{c}\text { Patient } \\
\mathbf{4} \\
\text { Dyad } \\
\text { No. }\end{array}$ & $\begin{array}{c}\text { Patient } \\
5 \\
\text { Dyad } \\
\text { No. }\end{array}$ & $\begin{array}{c}\text { Patient } \\
6 \\
\text { Dyad } \\
\text { No. }\end{array}$ & $\begin{array}{c}\text { Patient } \\
7 \\
\text { Dyad } \\
\text { No. }\end{array}$ \\
\hline $\begin{array}{ll}1 & \mathrm{~F} / \mathrm{S} \\
2 & \mathrm{~S} \\
3 & \mathrm{~F} / \mathrm{S} \\
4 & \mathrm{~S} \\
5 & \mathrm{~F} / \mathrm{S} \\
6 & \mathrm{~S} \\
7 & \mathrm{~F} / \mathrm{S} \\
8 & \mathrm{~S} \\
9 & \mathrm{~F} / \mathrm{S} \\
10 & \mathrm{~S} \\
11 & \mathrm{~F} / \mathrm{S} \\
12 & \mathrm{~S} \\
13 & \mathrm{~F} / \mathrm{S} \\
14 & \mathrm{~S} \\
15 & \mathrm{~F} / \mathrm{S}\end{array}$ & $\begin{array}{l}1 \\
8 \\
15 \\
16\end{array}$ & $\begin{array}{l}2 \\
9 \\
\\
17 \\
18\end{array}$ & $\begin{array}{l}3 \\
10\end{array}$ & $\begin{array}{l}4 \\
11\end{array}$ & $\begin{array}{l}5 \\
12\end{array}$ & $\begin{array}{l}6 \\
13\end{array}$ & $\begin{array}{l}7 \\
14\end{array}$ \\
\hline
\end{tabular}

\section{Theoretical framework}

The Erikson (1982) theory of 'eight stages of man' was chosen for the theoretical framework of this investigation. This theory describes the psycho-social human development as occurring through a series of eight crises: 1) trust-mistrust, 2) autonomy-shame/doubt, 3) initiative-guilt, 4) industry-inferiority, 5) identity-identity confusion, 6) intimacy-isolation, 7) generativity-stagnation and 8) integrity-despair extending from infancy, through adulthood and into old age. At each stage, the person incorporates earlier crises in the process of bringing into balance the tension that is now focused on, i.e. the most pronounced crisis, while the 
others are latent (Erikson 1982, Erikson et al. 1986). In each phase of life the person has to solve her/his phase-specific crisis but she/he must also resolve the previous crises and presolve her/his coming crises. The solving of crises is interwoven in a very complex way (Erikson 1988). When balancing between the two crisis poles the person develops either a virtue (strength) or a weakness (malignant tendency). Parallel with the scheme of crisis poles there is a scheme of virtue-weakness opposites; hope-withdrawal, will-compulsion, purpose-inhibition, competenceinertia, fidelity-repudiation, love-exclusivity, care-rejectivity, wisdomdisdain (Table 7) (Erikson 1982 pp. 32-34, Erikson et al. 1986).

Table 7. Life-cycle as described by Erikson's theory

\begin{tabular}{llcrl}
\hline & Positive pole & Virtue & Negative pole & Weakness \\
\hline I. & Trust & Hope & Mistrust & Withdrawal \\
II. & Autonomy & Will & Shame/Doubt & Compulsion \\
III. & Initiative & Gurpose & Guilt & Inhibition \\
IV. & Industry & Competence & Infiority & Inertia \\
V. & Identity & Fidelity & Identity confusion & Repudiation \\
VI. & Intimacy & Love & Solation & Exclusivity \\
VII. & Generativity & Care & Stagnation & Rejectivity \\
VIII & Integrity & Wisdom & Despair & Disdain \\
\hline
\end{tabular}

The old person's phase-specific crisis concerns integrity versus despair but she/he must also resolve the crises concerning 'trust versus mistrust', etc., to experience wholeness and meaning in her/his life and to develop a comprehensive sense of wisdom (Erikson et al. 1986). The Erikson couple and Kivnick (1986) state further that to experience generativity and thereby a sense of care, the old person must integrate her/his earlier life experience of caring into the next generations. To develop a sense of love, the old person must integrate her/his experience of intimate relationships (marriage, children, grandchildren) with her/his 
experience of isolation (loss of one's nears and dears, children's leaving home) during their whole life-cycles. They must also balance identity and identity confusion, as seen during her/his past, present and unknown future lives to a sense of fidelity. In her/his old age, a person continues to create a sense of competence based on her/his experience of industry versus inferiority during her/his life-cycle. To develop a sense of purpose in her/his old age she/he must balance initiative and guilt. It is not easy for her/him to find new kinds of activities and things to do because of her/his decreasing energy and sensory acuity. The tension between autonomy and shameldoubt concerns issues of control of one's own body, behaviour and whole life and makes a person experience a sense of will. In one's old age, with reducing capacity as a consequence of the deterioration of body and/or mind it is easy to feel shame or doubt and one needs support to keep one's sense of will. The first stage of one's life-cycle is characterized by the tension between basic trust and mistrust making a person develop a sense of hope if she/he has experienced support and response from her/his environment. In one's old age this crisis is closely related to essential wisdom. The crisis trust versus mistrust is also connected with the old person's relation to the numinous. Mutuality of recognition is ritualized.

\section{The Erikson theory applied to the demented patient}

A person suffering from a dementia disease has some difficulty in solving the present crisis and in resolving the past crises in a positive way. She/he is very vulnerable and needs a lot of support to be able to solve her/his crises, and experience wholeness and meaning in life (integrity).

It was assumed that the concrete care activities performed by caregivers among demented patients affect patients' experience of the crises of life. This seems logical because Erikson (1963) describes the child's experience of trust, etc. by referring to concrete care actions taken by its parents. He stresses, for example, the importance of the way the little child is helped to eliminate her/his body waste. In agreement with previous research (Norberg \& Sandman 1988, Hallberg et al. 1990 a, Kihlgren et al. 1993a, b) it was therefore presupposed that the demented 
can be supported or hindered to solve and resolve their life crises by the way everyday matters are handled.

\section{Analyses of the video-recorded morning care sessions}

The analyses were based on Ricoeur's philosophy (1971, 1976, Klemm 1983). It claims that there is always the dialectic of event and meaning in discourse. Ricoeur wants to bridge the gap between the phenomenological and the hermeneutical approaches. In phenomenology an experience is described so purely as possible without interpretation, but Ricoeur (1976) assumes that phenomenology describes only the event. In hermeneutics the event is interpreted to find the meaning behind it. Ricoeur (1976, $c f$. Klemm 1983) describes the process of interpretation as a series of steps.

\section{Fixation of texts}

The video-recordings were seen as texts ( $c f$. Ricoeur 1971). They were first watched to generate a sense of the whole. The video-tapes were then transcribed and a manuscript was produced which included verbal communication word by word, notes about turn-taking, paralingual and non-verbal communication (IV, V).

\section{Analysis of texts}

The written manuscript was analyzed in 2-minute sequences together with the corresponding sequence of the video-tape. A viewing of each sequence of the video-tapes and a first reading of the corresponding sequence of the manuscript were performed to acquire a sense of the whole of each sequence seen in the light of the Erikson theory (1982). A structural analysis of each 2-minute sequence was then made to elucidate the parts and how they related to each other. The coding concerned 1) which crises were supported or obstructed by the caregiver action in question; and 2) which crises the patient's reactions indicated. The notes concerned the two extreme poles of each crisis, such as trust versus mistrust. When more than one crisis was indicated all were registered. Thus the content of a sentence could be referred to one crisis, and the tone of voice to another. The caregivers could, for example, strengthen the patient's identity verbally and support her/his trust by her/his tone of voice while her/his industry was stimulated manually. The 2-minute 
sequences mostly included several crises. If both the negative and the positive poles of a crisis were relevant only the most evident pole was noted to make tendencies more clear, thus reducing the ambiguity of the communication.

The author and a bilingual co-worker coded the material independently of each other regarding which crises could be assumed to be affected by the action in question; each sequence was watched and read two to four times before it was coded. The codes that the investigators had noted were compared and if they disagreed (about $10 \%$ ) the investigators watched the video sequence again to come to an agreement about the coding. In the few remaining cases of disagreement (about 0.2 $\%$ ) no coding was performed for the crises concerned.

Comparisons were made between demented immigrants' relationship with bilingual and monolingual caregivers, for each respective patient. The Chernoff (1973) faces method of comparing similarities was used to group the relationship dyads, i.e. to sort and label the patterns of communication. Each morning care session was then interpreted as a whole. The viewing of the video-tapes and the reading of the manuscript as wholes were reflected upon and a short narrative was made for each morning care session interpreted in the light of the Erikson theory (IV).

The codes obtained in the analyses described (IV) were submitted to a factor analysis to elucidate the connection between the coded crises. Some calculation was done regarding all the crises indicated in the sessions taken together, comparing morning care sessions together with a bilingual caregiver with those with a monolingual caregiver. Statistical calculations were performed by use of Systat (Wilkinson 1989). The dimensions of the interaction were illustrated by modified musical notations developed by Johansson $(1987,1991)$ and previously used by Kihlgren and co-workers (1993a). The progression of each session was described (V).

Through these analyses of the interaction between the bilingual patient and her monolingual or bilingual caregiver new questions arose, for instance; what are these phenomena, that could be seen during the sessions but that could not be described by the Erikson (1982) theory.

In the next phase a phenomenological analysis was performed. The phenomenological method used here was inspired by Giorgi (1985, 
1988). It describes phenomena of lived experience and is based on the philosophy of Husserl $(1976,1977)$ and Merleau-Ponty (1974).

The following steps were taken:

A new fixation of the text of the video-recorded morning care sessions was made. There was an attempt to take as exact notes as possible to obtain a 'naive description' of the morning care sessions.

The descriptions were divided into two groups according to the relationship disclosed; positive or negative relationships. The negative descriptions consisted mainly of a lack of positive phenomena; only a few plainly negative actions were seen, such as belittling commands, negative use of power, repudiation. They were excluded from further analyses.

The text was divided into 'meaning units' in order to describe more directly the content of the interaction. On the basis of each meaning unit more abstractly 'formulated meanings' were given. The 'formulated meanings' were categorized and the categories were synthesized into themes (VI).

\section{The author's preunderstanding}

The author was born in Finland and Finnish is her native language. She immigrated to Sweden and worked for many years with demented patients. Therefore she had specific competence, and a valuable preunderstanding, for these studies. To diagnose the dementia correctly one bilingual physician and one bilingual psychologist were included in the research group.

\section{The ethical considerations}

Considerations regarding whether it would be ethically defensible to perform the reported studies on demented patients were made. in accordance with Norberg and co-workers (1985). The study was approved by the Ethics Committee at Umea University. The family members or relatives of the patients, the head physicians and the staff at the institutions housing these patients were contacted and informed consent to the investigation was obtained from both groups. Before each step of investigation the patient was asked for permission to perform the action in question. The video-recordings are stored safely in accordance with the research team's contract with the family members of the patients. 
Only the members of this research group have the right to see these video-recordings to secure the patients' integrity.

\section{RESULTS}

\section{$\underline{\text { Part I }}$}

\section{Time studies}

The time used in direct patient care activities varied between the different categories of staff. RNs spent $35 \%$ of their time in direct care while the corresponding percentage for ENs was $48 \%$ and for nurses' aids $55 \%$. The other time study showed that during hygiene and feeding the caregivers spent less time with helping demented patients than nondemented patients with similar needs for basic care (I).

\section{Caregiver interviews}

In the interviews the caregivers said that their reason to use less time with demented patients was that it was difficult to communicate with them; they do not need to talk to demented patients. The caregivers also described how they experienced the everyday care of the individual demented patient. All these patients had serious communicative problems. The caregivers emphasized that they worked according to routines, and not according to patients' needs, since they did not know enough about the patients' backgrounds and their demented patients were unable to tell them about their lives and interests. Five main types of patient reaction to the communicative attempts made by the caregivers were described: she/he enjoys contact, contact leads to aggression, she/he avoids contact, she/he reacts to contact only sporadically, or she/he does not react at all.

The caregivers' reactions to the demented patients' communication problems were discussed. Fourteen of twenty-one caregivers reported negative reactions, for instance; feelings of insufficiency, hopelessness, meaninglessness, burn-out, and loss of their commitment. Five caregivers reported positive reactions, for example they saw the patients as a challenge and felt happy when they had some response from them. Two caregivers thought that death would perhaps be the best alternative for severely demented patients. 
Fourteen of the twenty-one caregivers emphasized the importance of the patient's need for autonomy but they reported two types of problems relating to autonomy. First, it was difficult to know the patient's wish, so care was performed according to routines. Second, if the patient's wish was regarded as irrational, the caregiver felt that there was an ethical dilemma; the patient might hurt her/himself or others. The caregiver might feel that she/he had to use force against the patient, even when she/he wanted to respect the patient's autonomy. The care could be regarded as paternalistic (II).

\section{$\underline{\text { Part II }}$}

\section{Preconditions for the patients' communication}

The bilingual demented immigrants investigated had been given elementary education in Finland and held quite qualified positions, for example, they had their own businesses. Socially they had been well integrated as seen from the estimation of the size of their social network. These people immigrated to Sweden in connection with some personal or social crisis; such as the death of their husbands, economic difficulties or war. In Sweden they were settled in urban environments which meant increased demands to adapt as they had lived in rural areas in Finland. The immigrants did not have adequate training in Swedish and had more unqualified jobs than they had had in Finland. They developed introvert interests, for instance Finnish literature, music and house-keeping.

The investigations regarding their diagnoses showed that all patients who had been selected for the studies suffered from moderate, or severe, dementia. The MMSE varied between 1 and 16, and the GDS ranged from 5 to 7 . When the neuropsychological tests were performed in Finnish expressive speech turned out to be much better preserved than impressive speech in all patients.

The observation of the investigated patients' communication and performance of practical tasks showed that they communicated and managed tasks better together with a Finnish-speaking caregiver. All of them were able to communicate adequately with a Finnish-speaking caregiver, whereas with a Swedish-speaking caregiver there were serious problems and the communication was characterized as one-way communication with a great many commands (III). 
Relationship between demented patients and their monolingual and bilingual caregivers

\section{Patterns}

Three different patterns of relationship were seen; positive, mainly positive (mixed) and negative relationships. The bilingual caregivers' relationship with demented bilingual patients was labelled positive or mainly positive, while the monolingual Swedish-speaking caregivers had severe problems to communicate with the same patients and their relationship to the patients was labelled negative. One monolingual Swedish-speaking caregiver could communicate positively with two patients so the relationship was labelled positive. Both patients spoke Swedish quite well and did not mix their two languages. This caregiver's educational level was higher than that of the other monolingual caregivers.

The positive relationship was characterized by the caregivers' supportive communication concerning crises Nos. 1-6 (Erikson 1982). One caregiver often communicated even positively regarding crises Nos. 7-8. The negative relationship was characterized by the caregivers' negative communication concerning crises Nos. 1-6 and 8. Here, the patients reacted to the caregivers' negative interaction. In these negative relationships the caregivers supported the patients' identity best (crisis No. 5). The patients seemed to be more confused when the communication did not function positively or when the verbal and nonverbal communication did not agree. In the mixed relationship the caregivers and the patients communicated both positively and negatively concerning the crises Nos. 1-6 (IV).

\section{Dimensions and progression}

The factor analysis of the material interpreted as described above (IV) showed a connection between the patients' actions/reactions implying different crises. The crises trust versus mistrust, autonomy versus shame and doubt, industry versus inferiority, and intimacy versus isolation were lumped together into one factor. The crises initiative versus guilt, identity versus identity confusion, generativity versus stagnation, and integrity versus despair seemed to be separate factors and, accordingly, five factors were accepted. 
The bilingual caregivers' interaction with the bilingual patients was multidimensional and the crises seemed to be promoted hierarchically, i.e. the 'highest' crisis in the hierachy also included the promotion of the 'lower' crises ( $c f$. Erikson 1982). The monolingual Swedish-speaking caregivers communicated negatively and did not promote the patients in their solution of the crises. Their interaction was not multidimensional and the crises were not promoted hierarchically, i.e. a 'higher' crisis could be positively met without a 'lower' crisis having been positively met first.

The progression of the interaction differed between the dyads previously assessed as positive, negative and mixed. Mostly positive interaction started positively and the proportion of positive codes increased both in the caregiver's and her patient's communication. Thus, there was, for example, an increase in the proportion of positive codes; starting with the promotion of the first six dimensions the caregiver reached as for the last two crises at the end of the interaction. In some cases the patient started by showing mistrust but soon changed to trust when she found that her caregiver understood her.

In negative interaction the caregiver usually started quite positively while the patient started less positively. During the first third of the interaction period the proportion of negative codes increased for both caregiver and patient, more so for the caregiver. A few dyads were very negative during the whole interaction. There were some interactions where the patient showed a small increase in positive communication during the third part of the interaction $(\mathrm{V})$.

\section{Characteristics of the relationship between patient and caregiver}

The following themes were identified in the phenomenological analysis of the video-recorded morning care episodes; caregiver's virtues, respect for patient, communion, will, and joy. The characteristics of the positive relationship were described.

The theme labelled 'caregiver's virtues' covers descriptions of characteristics such as honesty, generosity, consideration, tenderness, and patience. The theme labelled 'respect for patient' covers descriptions indicating that the caregiver regards the patient as a valuable and unique person. 'Communion' covers descriptions of an interaction sequence between patient and caregiver, where they show mutual symbolic 
understanding. The themes labelled 'will' and 'joy' cover descriptions of the caregiver's showing interest in the patient, providing help if the patient wants it. The actions are performed in a manner that shows that the caregiver does them freely and willingly and enjoys helping the patient (VI).

\section{DISCUSSION}

The relationship between the patients and their caregivers is the core of caregiving. A relationship is based on the interaction between the parties. Communication is a means of interacting ( $c f$. Ringler 1983). There are severe difficulties in communicating with the demented verbally as well as non-verbally because of their symptoms of dementia (APA 1987, Bayles \& Kaszniak 1987, Asplund et al. 1991b, Bayles 1991, Bohling 1991, Asplund et al. 1993, Jansson et al. 1993). The communication problems are even greater for demented immigrants as the problems connected with their dementia add to those of their bilingualism (Hyltenstam \& Stroud 1989, in press).

The studies reported in this thesis concern the communication between monolingual and bilingual demented patients and their monolingual/ bilingual caregivers. Various kinds of methods have been used to illuminate communication, interaction and relationship in general.

The aim of this discussion is to relate the findings to each other and to the theoretical framework of the Erikson (1982) theory of 'eight stages of man'. Verbal communication is discussed from the point of view of the importance of language to the establishing of human relationships.

\section{Critique of the methods used in the study}

During the course of the study the research paradigm changed. The study was planned in accordance with system theoretical and behaviouristic thinking. However, the findings of the investigation, the study of literature, and the discussion with colleagues made the author adopt a phenomenological-hermeneutical view of research and life. This means that some of the data collected early in the study were not used in the thesis and some data that would have been needed were not collected. The most apparent mistake was that the demented patients were not 
interviewed about their experience. They were regarded more as objects than as subjects during the planning of the study.

In the first time study (I) self-assessments performed by the caregivers were used but independent non-participant observations should have been used instead. However, the self-assessment method was chosen for financial reasons. In the literature both methods have been described and especially the self-assessment method has often been used in Scandinavia (e.g. Hultén et al. 1969, HYKS 1981). According to Ball and co-workers (1984) there are problems with this method (it is, for example, difficult to remember to note all one's tasks) when caregivers assess their own use of time in various care situations.

In the interviews (II) about the ethical aspects of the care of demented patients only ENs and nurses' aids were interviewed. Had the other professions and the patients' families been included, a more multidimensional picture would have emerged. Nilstun (1992) critizes this and emphasizes that the authors have not discussed the ethical principles of 'justice' and 'sanctity of life' enough. However, in the interviews the main objective was not to study the application of ethical principles but to discuss caregivers' experience of the care of demented patients with communication problems. Problems relating to the principles of autonomy, beneficence and non-maleficence were accounted for by the caregivers. This is in agreement with the findings of interviews with ENs and RNs concerning dementia care ( $\AA$ kerlund \& Norberg 1985, Jansson \& Norberg 1992). Swedish caregivers did not emphasize problems relating to the ethical principles of justice and sanctity of life, which, for example, caregivers in Israel did (Norberg \& Hirschfeld 1987, Kuuppelomäki \& Lauri 1991).

In part II of the study there is a lack of agreement between the neuropsychological examination and the linguistic investigation. This may be due to the fact that the neuropsychological examination was performed one year after the linguistic investigation. It was evident that patients Nos. 7-9 had suffered a pronounced cognitive decline during this period (III).

Regarding the phenomenological-hermeneutic analysis presented in papers IV and $\mathbf{V}$ the theoretical perspective had been decided on before the analysis started. Thus alternative perspectives were not considered before the first interpretation of the morning care sessions. According to the method inspired by Ricoeur (1976) the interpretation process should 
start with a naive reading leading to a guess which is validated in the structural analysis of the text. As the first analyses of the text proceeded, the assumption that the Erikson theory would be a rewarding perpective for the analysis was part of the author's preunderstanding of the lived experience of being demented, which, in turn, was based on previous research (Norberg \& Sandman 1988, Hallberg et al. 1990b, Kihlgren et al. 1993a, b). After a first ('naive') reading of the transcribed text and the watching of the video-recordings it was assumed that an interpretation in accordance with the Erikson theory would give a valid picture taking most of the text into account. This assumption was validated through the structural analysis.

As it seemed essential also to consider other possible interpretations and to choose the one that would give the most comprehensive picture, taking most of the text into account, and agreeing with previously accepted interpretations, the analysis presented in paper VI was undertaken. Although a phenomenological method was applied, presupposing pure descriptions (Giorgi 1985), the author regards the result as an interpretation. It seems impossible for descriptions to be free from interpretations as the mere use of language means interpreting (Klemm 1983 pp. 92).

The interpretation obtained in the analysis presented in paper VI did not seem to be an alternative to the interpretation in papers IV and $\mathbf{V}$ but a complement. It is evident that a video-recorded morning care session is so multidimensional that its meaning cannot be made explicit only by one analysis.

When the results of the analyses presented (IV, V) were compared with those of the analyses performed by Kihlgren and co-workers (1993a, b) it was evident that, despite minor differences in the method, the same general picture emerged; when the demented patient's integrity was promoted by the caregiver's way of interacting, the patient disclosed unexpected ability.

The arguments in favour of these considerations relate to Riceour's thoughts (1976 pp. 75). A text can be seen from several angles but never from all angles at once. Thus it is open to several readings. Validation does not mean verification. Validation means arguing that an interpretation is probable in the light of what is already known. An 
interpretation is regarded valid when it is not only probable but also more probable than another interpretation.

\section{The demented patients' preconditions for communication}

The preconditions of the demented Finnish immigrants of this study to communicate with their Swedish-speaking caregivers were poor (III). Some of the patients spoke only Swedish though they had used both languages actively during their time in Sweden. Four of the five patients of the group that had preserved their ability to make an appropriate language choice, were the same patients as those who had also reached a high level of proficiency in their second language (Hyltenstam \& Stroud in press). All patients communicated adequately with their Finnishspeaking caregivers (III).

These demented immigrants had much more limited social networks in Sweden than in Finland which is in agreement with the results of previous studies (Jaakkola 1983, Haavio-Mannila 1986). It is possible that they became socially more isolated and therefore had less chance to practice Swedish.

Thus both their diseases and their social situation seem to be a poor precondition for communication, interaction, and for the establishing of a positive relationship with their Swedish-speaking caregivers.

\section{Interpretation of the consequence of migration in the light of the Erikson theory}

The Erikson theory $(1963,1964,1977,1982,1988$, Erikson et al. 1986) was used for the theoretical frame of the phenomenologicalhermeneutical analysis (IV, V). Joan and Erik Erikson have developed this theory of man's life cycle. The individual must balance the positive and negative poles of each of the eight crises to find a positive solution to them. If some of the crises have not been solved in a positive way previously there is the risk for a negative development of this stage; a weakness may occur. The crises can be resolved in a new crisis. The crises which have been solved more negatively in the earlier stages may be especially difficult in the coming crises.

The immigrants may experience the migration process as a crisis and must presolve their future crises and resolve their previous crises in their 
new situation. Migration may be caused by negative events in the home country, such as war or personal and social crises, (III) and thereby causing more difficulties during the adaptation to the new situation and the migration process. If the immigrants do not find their environment good enough or have to face belittlement, disgust and discriminatory attitudes, they may develop basic mistrust of life, of others and of themselves instead of basic trust. Some kind of alienation (withdrawal) occurs. Great demands are made on the immigrants by their environment, and by themselves; they are expected to perform well and not "screw up". It is difficult to experience autonomy in this situation, and shame and doubt are common feelings. When failing one may experience shame, and a sense of compulsion. Failure causes guilt and one becomes passive, taking no initiative. It can be very difficult to develop a sense of purpose. When immigrants arrive in the new country they usually have both education and work experience and their experience of industry and of competence was quite good. Suddenly this previous knowledge is not valid any more and they must start from 'scratch'. They cannot have the job they were trained for. Washing up or cleaning in restaurants or institutions, when, for instance, they have an academic degree in their home countries, increases their feeling of inferiority which may result in a sense of inertia. Identity is a result of continuity; people must be able to recognize themselves. They must know what they used to be, what they are today and what they expect to be in the future. Identity presupposes that the picture they have of themselves is confirmed by other people. Immigration means a break in the continuity of identity. It is also difficult for them to be confirmed by other people's picture of them because their environment may have a view of immigrants, which is not compatible with the view they have of themselves. There is a great risk of identity confusion and repudiation. Only those who are sure of their own identity can share it with others and feel intimacy and create the virtue of love. There is the risk of divorce which has been reported to be common among Finnish immigrants in Sweden (Majava 1981). The same tendency can be seen in this study (III). There is a considerable risk of isolation and of a sense of exclusivity because they are not in communion with their environment. If people cannot experience feelings of communion and love and have difficulties with their identity, they become doubful about their future; it becomes difficult for them to take part in care of 
others and experience generativity. This may, for instance, take the form of inferiority and passivity in society. A sense of rejectivity may occur. If immigrants have not been able to remedy the negative effects of the stages mentioned earlier they feel repentance, despair and hopelessness instead of integrity (wholeness and meaning) in their lives. When they feel that death is approaching and feel lonely they may start hoping to be laid to rest in their former countries. Since this is not easily done it may create deep anguish and disdain instead. Only if they have solved positively at least most of the mentioned crises, can they reach a greater understanding of life, tolerance and a deeper feeling of communion in the 'new' country, thus experiencing a sense of wisdom.

\section{Care of the demented monolingual and bilingual patients}

\section{Time}

The time studies (I) showed that the demented patients were given less time by their caregivers for hygiene and feeding than the nondemented patients with the same needs for basic care. A reason the caregivers gave for this was that they could not communicate with these patients and it was easier to 'take over' and carry out the care tasks without talking with the patient. Part II of these studies indicated that during the morning care sessions (IV) the time used with the patient is an important aspect of promotion of integrity according to the Erikson theory (1982). It is difficult to promote the generativity versus stagnation and integrity versus despair crises without enough time. The fact that the patient is naked, or partly naked, during the morning care makes the situation sensitive. The caregiver needs time to talk with the patient after the morning care has been completed and the patient has been dressed again, to ensure that the patient is left with a feeling of dignity.

Time is a very important aspect of the interaction between patients and their caregivers. This has, for example been illustrated by LeinoKilpi (1990) and Liukkonen (1990) in their studies about good nursing care. Clarke and Wheeler (1992) stressed that one of the most common hindrances to a good relationship in caring is the lack of time in the interaction with patients. Armstrong-Esther and Browne (1986) investigated the nurse-patient interaction on a geriatric ward. Their results showed that nurses interacted significantly less often with confused patients than with lucid patients. Hallberg and her co-workers (1990a) 
found that caregivers spent less time on social interaction with vocally disruptive demented patients than with other demented patients. Time must be an extremely important aspect of the care of demented patients because they need more time to respond to incoming messages (unpublished results).

The finding that the caregivers of monolingual demented patients did not think it worth while communicating with their patients and therefore used less time for their care than for that of non demented patients can in the light of the findings of paper VI be taken to indicate that the caregivers did not respect their patients as unique and valuable people. When they do not give the patients the time needed to express themselves $(c f . \mathbf{I V}, \mathbf{V})$, there is a risk that their expectations are met, i. e. the patients cannot express their wishes so their autonomy is not respected (VI). There is a negative spiral.

\section{Ethical aspects}

The caregivers discussed their care situation from an ethical point of view (II). Nearly all of them agreed about the importance of the demented patient's autonomy but in the practical situations there were many complications because of the communication problems. The caregivers often faced ethical dilemmas. The interviews were taken to indicate that mostly they had to act paternalistically, thus giving priority to the ethical principles of beneficence/non-malificence. This is in accordance with findings based on interviews with RNs regarded as good and experienced in the care of demented patients (Jansson \& Norberg 1992). It seems reasonable to assume that demented immigrants have more problems than 'natives' to inform their caregivers, who do not know their language, about their wishes and therefore have fewer possibilities to autonomy. Furthermore, the study showed that mostly demented immigrants had their families in Finland (unpublished). This lack of information about patients' preferences may result in more undifferentiated care, i.e. the care is a result of routines rather than of patients' individual needs.

\section{Preconditions for communication}

The demented immigrants studied had severe difficulties in their language choice and language separation but they were able to communicate adequately in Finnish (III). Some of these demented 
patients seemed to function on a higher competence level than they had been estimated to do by the Swedish-speaking physicians and therefore it is quite possible that they were placed on an inadequate care level.

\section{Relationship}

There was a connection between the caregiver's ability to communicate in Finnish and the crises (Erikson 1982) supported in the interaction between bilingual demented patients and their monolingual/bilingual caregivers during morning care sessions. Bilingual Finnish-Swedish speaking caregivers promoted the solution of crises mostly whereas monolingual Swedish-speaking caregivers mostly hindered the solution of crises. The trust versus mistrust, autonomy versus shame and doubt, industry versus inferiority, and intimacy versus isolation crises seemed to be the crises that were the most sensitive to the caregiver's language (IV, V).

One problem seemed to be that the monolingual caregivers did not understand the patient, while the patient understood the caregiver but was unaware that she herself used the inadequate language. Most of the support was given to the patient's experience of identity both by monolingual and bilingual caregivers. The promotion of the generativity versus stagnation and integrity versus despair crises seemed connected with extremely long morning care sessions (IV, V).

The Erikson theory has previously been used as a theoretical frame by Hallberg and co-workers (1990b) in a study of the interaction between vocally disruptive demented patients and their caregivers. Their results showed that the caregivers mostly supported the patients' identity. The support usually aimed at orienting the patient to person, time and place, which is in agreement with this study of bilingual demented patients (IV, V). The reason for these results may be the training of caregivers in long term care in Sweden which has given special emphasis to the importance of supporting identity.

Kihlgren and co-workers (1993a, b) also studied interaction in the light of the Erikson theory. They found that the training of caregivers in integrity promoting care based on the Erikson (1982) theory resulted in a more positive interaction and support for most of the crises. This led to the patients' displaying greater and greater ability (Kihlgren et al. 1993a). A positive spiral of mutual interaction was created. Furthermore 
Kihlgren and her co-workers (1993b) claim that supporting the crises concerning trust, autonomy and intimacy at the beginning of the morning care session was very important to the development of interaction.

\section{Caring in mutual recognition, communion and love}

Caring is more than adequate techniques. It is a transactional relationship with deep meaning, where the caregiver meets the patient's individual needs, and the patient's interests, on the highest possible level (Paterson and Zderad 1988). Caring is a relationship that develops with the changes in the person who cares and in the person cared for (Mayeroff 1965). According to Hegel (1967, pp. 229) the human being becomes conscious of her/himself only by being recognized by another human being. There is a process of mutual recognition of one another. Applied to the care of demented patients this means that caregivers obtain their recognition through their demented patients and their perception of the patients will therefore colour their perception of themselves. Through this mutual recognition a real 'meeting' may occur where the caregivers show respect for the patients and recognize them as human beings equal to themselves in value ( $c f$. Buber 1958). This kind of care has been described by Asplund (1991 pp. 25-26). Gustafsson and Pörn (1992) also underline the importance of confirmation in care. The findings presented in paper VI remind of their interpretation of the phenomenon confirmation. They mean that confirmation is characterized by respect, interest, understanding and competence.

According to Arendt (1958) human beings disclose themselves through their actions. For demented patients this disclosure may be very unclear and vague at first due to the symptoms of the disease. The question is whether or not the caregivers can recognize the patients as human beings despite this. By recognizing patients as human beings caregivers confirm them, and help them disclose themselves more clearly (cf. Kihlgren et al. 1993b).

It seems reasonable to assume that demented immigrants and their bilingual caregivers can recognize each other through the language they share. Language is not only a means of communication but a particular view of the world (Gadamer 1988 pp. 398). Having a language means having a world. Speaking a language means disclosing a world. Speaking the same language thus means sharing a world. 
When demented immigrants speak Finnish, Finnish caregivers cannot only understand more easily what they try to communicate but they can also understand more easily the world, that is disclosed by the patients' speech, and embraces their messages. Vice versa, patients can more easily not only understand caregivers' messages but also the world that they disclose. Thus there may be communion between patients and caregivers, i. e. the sharing of a world ( $c f$. Gadamer 1988 pp. 111, 117).

Referring to Hegel (1967 pp. 229) it seems reasonable to assume that the caregivers who share their patients' world can recognize them more easily as individuals within this world. When patients are recognized they are easier to respect. The patient's recognition of the caregiver also confirms the caregiver as a person. The caregivers disclosed virtues that seemed important to their ability to recognize the patients (VI); for example they showed patience, which means that they were willing to wait for the patients to disclose themselves.

Florensky (Slesinski 1984 pp. 133, 141) emphasized the connection between the knowledge of truth and love. The knowledge of truth is 'communion in love'. Knowing God means loving him. Analogously, it seems reasonable to assume that recognizing the demented patient as a human being means loving her/him. There is also a knowledge about, that does not presuppose love. The demented patient is known as an object ( $c f$. Athlin et al. 1989). No real 'meeting' occurs.

The positive relationship between demented immigrants and their bilingual caregivers (IV-VI) may not only depend on the verbal language per se. The ability to recognize the melody of language develops before a human being is able to use verbal language (Merleau-Ponty 1973). It seems likely that severely demented patients recognize, and feel at home with, the melody of their mother tongue. Furthermore, socially ritualized care activities may also be relevant. Through the ritualization of daily routines the child learns 'the only proper way to do things' such as eating, and taking a bath. The child learns to grasp the symbolic meaning of these activities of everyday life. The satisfaction of immediate needs is elevated into a community context (Erikson 1977 pp. 80). The child learns these 'meanings' through its mother's ways of handling its everyday care. Finnish caregivers may disclose some of this cultural ritualization in their way of helping the patient with everyday activities. There may be a Finnish way of performing some tasks. As demented patients have 
problems with their abstract thinking and with remembering sequences of action (APA 1987) it is utterly important that the small details of everyday care are performed in a way that discloses love for the patient and reminds her/him of the 'only proper way' she/he learnt as a child. This seems especially important since there is some support for the hypothesis that severely demented patients undergo regression (Reisberg 1986, Sandman et al. 1990, Asplund et al. 1991a, Ericsson 1993).

\section{Interpretation of the findings seen as a whole}

When the negative interaction described in papers $I$ and II is interpreted from the perspective disclosed in paper VI, it seems evident that the caregivers had no respect for the patient, or will to help. Being able to help did not fill them with joy. Neither were they in communion with them.

The finding (II) that the caregivers who could not communicate with their demented patients felt that they had lost their commitment can be understood in the light of Hegel's (1967) description of the importance of one person recognizing her/himself in another person. When the caregiver does not value the patient, being recognized by the patient is not regarded as valuable, which means devaluating the caregiver her/himself ( $c f$. Asplund 1991 pp. 30). The phenomenon can also be elucidated by reference to Goffman's (1970 p. 122) description; when a person has to stay together with another person that she/he does not get into contact with, it is so frustrating that she/he seeks to shorten the 'meeting'. It may be that the lack of contact between patient and caregiver makes the caregiver's trying to find excuses not to stay with the patient longer than necessary. A negative interaction spiral starts. This suggestion is supported by the findings of Akerlund and Norberg (1990) that caregivers tried very hard to find meaning in a severely demented patient's utterly weak expressions to find some meaning in their care of her.

The finding that there was love in the relationship between bilingual caregivers and bilingual demented patients seems surprising (VI). Why should Finnish-speaking caregivers be more loving than Swedish-speaking caregivers? It seems reasonable to assume that the results do not indicate that Finnish-speaking caregivers were initially more loving than Swedishspeaking caregivers. What was registered was not an emotion in the 
caregivers but love as incarnated in the care activities. Thus the care activities are regarded as open to interpretations that decide their meaning (Ricoeur 1971 p. 544). Love as registered in the video-recordings can also be seen as a quality-mark of the everyday care activities ( $c f$. Watzlawick et al. 1967 pp. 51).

The finding that bilingual caregivers have a better precondition for establishing contact with their patients makes it reasonable to assume that a positive interaction spiral is initiated. When caregivers get into contact with demented patients they can recognize their patients and value them and therefore experience patients' recognition of them as rewarding ( $c f$. Hegel 1967 pp. 229). As their contact with the patients is rewarding they become motivated to stay with the patients ( $c f$. Goffman 1970 p. 122). The positive spiral is reinforced.

When patients suffer from dementia, their experience of the world becomes fragmentary (Hallberg 1990, cf. Melges 1983 pp. 55-58). It seems reasonable to suggest that the fragmentation can be more apparent when the patients have changed countries and cultures. They may have experienced more and more problems in their solving of the life crises because of the difficulties of the adaptation during the migration process resulting in basic weaknesses (malignant tendencies) (Erikson et al. 1986). Therefore bilingual demented patients can be expected to need even more support from caregivers than monolingual demented patients.

Zingmark and her co-workers (accepted) found that a feeling of not being at home was an everyday ordeal for severely and moderately demented patients. It seems logical to assume that if caregivers speak the patients' mother tongue and perform the everyday activities in 'the proper way', this may help create an experience in the patients of being at home which seems to be another expression for the experience. of wholeness and meaning (integrity).

Thus on the basis of this thesis it is recommended that special units are created where bilingual caregivers take care of the bilingual demented patients. 


\section{ACKNOWLEDGEMENTS}

This study was made at the Department of Advanced Nursing, Umeå University, and the Department of Geriatric Medicine, the Karolinska Institute, Stockholm.

Several people have contributed in one way or other. I would very much like to express my gratitude to everyone, who has been helpful, understanding and supportive during this time.

Heartfelt thanks are due to:

Professor Astrid Norberg, Head of the Department of Advanced Nursing, Umeå University, for warm 'maternal' supervision and angelic patience with my numerous peculiarities, for example, my use or abuse, of prepositions, both in Swedish and in English.

Professor Bengt Winblad, Department of Geriatric Medicine, Karolinska Institute, Stockholm, for 'paternal' supervision telling me, for example, 'shut your eyes and jump-I'll support you'. This was the first illustration of the promotion of trust in my scientific development.

My co-workers, my friends, Associate Professor Matti Viitanen and psychologist Tarja-Brita Robins Wahlin, for participating and helping in various parts of these studies.

Associate Professor Sture Eriksson, Umeå, for his patience when introducing me to the 'terrifying' world of statistics.

Professor Kenneth Hyltenstam and his wo-workers, Christoffer Stroud, PhD, and Eija Kuyumcu, BA, the Centre for Research on Bilingualism, Stockholm University, for generous sharing of their results from the linguistic examinations of the investigated patients.

My colleagues at the Department of Advanced Nursing in Umeå, for all the laughing, and crying and for the warmest and most creative work milieu of the whole world, and Inga-Greta Nilsson and Judy Hedlund in particular for all the kinds of help and understanding they showed.

My colleagues at the Department of Geriatric Medicine in Umeå and Stockholm, for friendship and sympathy during the time, and Ms Eva Rimsjö in particular for her kind way of informing me of the where abouts of a certain person, who is mostly somewhere else.

I would also like to thank:

All patients, their families and staff for their support and co-operation.

All my friends for supporting and being there when I needed them most.

My mother, my sisters and brothers and their families for believing in my ability to 'move mountains'.

Last and most - millions of thanks to my husband Kari for giving me the 'impulse' to undertake this major job and to him and our children, Pia and Minna, for their patience, never-ending support, love and first-rate 'home help service'.

The study was supported by grants from the Swedish Medical Research Council (grant No. 9246), Stockholm County Council, Västerbotten County Council, The Joint Committee of the Northern Health Region of Sweden, Umea University, Delegation for Social Research, and the Delegation for Immigrant Research. 


\section{REFERENCES}

Abeysinghe S., Bayles K., and Trosset M. (1990). Semantic memory deterioration in Alzheimer's subjects: evidence from word association, definition, and associate ranking tasks. Journal of Speech and Hearing Research, 33, 574-582.

APA (American Psychiatric Association). (1987). Diagnostic and Statistical Manual of Mental Disorders. 3rd ed. Revised, (DSM-III R). American Psychiatric Association, Washington DC.

Arendt H. (1958). The Human Condition. The University of Chicago Press, Chicago.

Armstrong-Esther CA., and Browne KD. (1986). The influence of elderly patients' mental impairment on nurse-patient interaction. Journal of Advanced Nursing, 11, 379-387.

Asplund K. (1991). The Experience of Meaning in the Care of Patients in the Terminal Stage of Dementia of the Alzheimer Type. Interpretation of Non-verbal Communication and Ethical Demands. Umeå University Medical Dissertations, New Series No 310, Umeå University.

Asplund K., Jansson L., and Norberg A. (1993). Expressive facial behaviour in patients with severe dementia of the Alzheimer type (DAT). A comparison between unstructured naturalistic judgements and analytic assessments by means of the facial action coding system (FACS). International Psychogeriatrics, in press.

Asplund K., Norberg A., and Adolfsson R. (1991a). The sucking behaviour of two patients in the final stage of dementia of the Alzheimer type. Scandinavian Journal of Caring Sciences, 5, 141-147.

Asplund K., Norberg A., Adolfsson R., and Waxman H. (1991b). Facial expressions in severely demented patients. - A stimulus-response study of four patients with dementia of the Alzheimer type. International Journal of Geriatric Psychiatry, 6, 599-606. 
Athlin E., Norberg A., Asplund K., and Jansson L. (1989). Feeding problems in severely demented patients seen from task and relationship aspects. Scandinavian Journal of Caring Sciences, 3, 113-121.

Ball JA., Goldstone LA., and Collier MM. (1984). Criteria for Care. The Manual of the North West Nurse Staffing Levels Project. Polytechnic Products, Newcastle upon Tyne, pp. 59.

Bayles K. (1991). Age at onset of Alzheimer's disease. Relation to language dysfunction. Archives of Neurology, 48, 155-159.

Bayles K., and Kaszniak A. (1987). Communication and Cognition in Normal Aging and Dementia. Little Brown Company, London.

Beauchamp TL., and Childress JF. (1983). Principles of Biomedical Ethics. 2nd ed. Oxford University Press, New York.

Bohling H. (1991). Communication with Alzheimer's patients: an analysis of caregiver listening patterns. International Journal of Aging and Human Development, 33, 249-267.

Bolander M. (1989). Prefabs, patterns and rules in interaction? Formulaic speech in adult learners' L2 Swedish. In K. Hyltenstam and LK. Obler (Eds.) Bilingualism Across the Lifespan. Aspects of Acquisition, Maturity and Loss, Cambridge University Press, Cambridge, pp. 73-86.

Broderic P., and Laszlo JI. (1987). The drawing of squares and diamonds: A perceptual-motor task analysis. Journal of Experimental Child Psychology, 43, 44-61.

Buber M. (1958). I and Thou. 2nd ed. (German original, 1923). Charles Scribner's Sons, New York.

Bäckman L., and Karlsson T. (1986). Episodic remembering in young adults, 73-year-olds and 82-year-olds. Scandinavian Journal of Psychology, 27, 320-325. 
Chernoff H. (1973). Using faces to represent points in k-dimensional space graphically. Journal of the American Statistical Association, 68, 361-368.

Christensen A-L. (1984). Luria's Neuropsychological Investigation. (Swe). Berlings, Arlöv.

Clarke JB., and Wheeler SJ. (1992). A view of the phenomenon of caring in nursing practice. Journal of Advanced Nursing, 17, 1283-1290.

Clyne M. (1977). Bilingualism of the elderly. Talanya, 4, 45-56.

Clyne M. (1987). Constraints on code switching: how universal are they? Linguistics, 25, 739-764.

Condon WS. (1980). The relation of interactional synchrony to cognitive and emotional processes. In M. Ritchie Key (Ed.) The Relationship of Verbal and Nonverbal Communication. Mounton Publishers, New York, pp. 49-65.

Critchley M. (1964). The neurology of psychotic speech. British Journal of Psychiatry, 110, 353-364.

Della Sala S., Lucchelli F., and Spinnler H. (1987). Ideomotor apraxia in patients with dementia of Alzheimer type. Journal of Neurology, 234, 9193.

Ericsson K., Holmén K., Jorm A., Forssell L., Almkvist O., Rönnberg L., and Winblad B. (1993). A short drawing scale for the assessment of cognitive dysfunction in old age. European Journal of Gerontology, in press.

Erikson EH. (1963). Childhood and Society. 2nd ed. WW. Norton \& Company, New York.

Erikson EH. (1964). Insight and Responsibility. WW. Norton \& Company, New York.

Erikson EH. (1974). Dimensions of a New Identity. WW. Norton \& Company, New York. 
Erikson EH. (1977). Toys and Reasons. Stages in the Ritualization of Experience. WW. Norton \& Company, New York.

Erikson EH. (1982). The Life Cycle Completed. WW. Norton \& Company, New York.

Erikson EH., Erikson JM., and Kivnick Q. (1986). Vital Involvement in Old Age. The Experience of Old Age in Our Time. WW. Norton \& Company, New York.

Erikson JM. (1988). Wisdom and the Senses. The Way of Creativity, WW. Norton, New York.

Erkinjuntti T. (1988). Dementia. Clinical Diagnosis and Differential Diagnosis, with Special Reference to Multi-Infarct Dementia. Academic Dissertation, Helsinki University.

Erkinjuntti T., Laaksonen R., Sulkava R., Syrjäläinen R., and Palo J. (1986). Neuropsychological differentiation between normal aging, Alzheimer's disease and vascular dementia. Acta Neurologica Scandinavica, 74, 393-403.

Folstein MF., Folstein SE., and McHugh PR. (1975). "Mini-Mental state". A practical method for grading the cognitive state of patients for the clinician. Journal of Psychiatric Research, 12, 189-198.

Gadamer H-G. (1988). Truth and Method. 2nd ed. (German original, 1975). Sheed \& Ward, London.

Giorgi A. (1985). Phenomenology and Psychological Research. (Ed.) Duquesne University Press, Pittsburgh.

Giorgi A. (1988). Validity and reliability from a phenomenological perspective. In J. Baker (Ed.) Proceedings of the Second Biannual Conference of the International Society for Theoretical Psychology, April 20-25, 1987, Alberta, Canada, New York Springler Vlg., New York.

Goffman E. (1970). Interaction Ritual. (Swedish translation). Aldurs/Bonniers, Stockholm. 
Gottfries CG., Bråne G., Gullberg B., and Steen G. (1982). A new rating scale for dementia syndromes. Archives of Gerontology and Geriatrics, $1,311-330$.

Grosjean F. (1982). Life with Two Languages. An Introduction to Bilingualism. Harvard University Press, Cambridge, MA, pp. 113-166.

Gustafsson B., and Pörn I. (1992). A motivational approach to confirmation. An interpretation of some dysphagic patients' experiences. In Gustafsson B. Living with Dysphagia. Some Aspects of the Experiential Meaning of Handicap, Adaptedness and Confirmation. Medical Dissertation. Karolinska Institute, Stockholm, paper No IV.

Haavio-Mannila E. (1986). Elderly Finnish Immigrants in Sweden. (Swe). Modin-Tryck AB, Stockholm.

Hachinski VC., Iliff LD., Zilhka E., duBoulay GH., McAllister VL., Marshall J., Russell RWR., and Symon L. (1975). Cerebral blood flow in dementia. Archives of Neurology, 32, 632-637.

Hallberg IL. (1990). Vocally Disruptive Behaviour in Severely Demented Patients in Relation to Institutional Care Provided. Umeå University Medical Dissertations, New Series No 261, pp. 11-14.

Hallberg IL., Luker K., Norberg A., Johnsson K., and Eriksson S. (1990a). Staff interaction with vocally disruptive demented patients compared with demented controls. Aging, 2, 163-171.

Hallberg IL., and Norberg A. (1990). Staff's interpretation of the experience behind vocally disruptive behaviour in severely demented patients and their feelings about it. International Journal of Aging and Human Development, 31, 297-307.

Hallberg IR., Norberg A., Jonsson K., and Eriksson S. (1990b). Verbal interaction during the lunch-meal between caregivers and vocally disruptive demented patients. In I. R. Hallberg, Vocally Disruptive Behaviour in Severely Demented Patients in Relation to Institutional Care Provided. Umeå University Medical Dissertations, New Series No 261, pp 143-164. 
Hallberg IL., Edberg AK., Nordmark Å., Johnsson K., and Norberg A. (1993). Daytime vocal activity in institutionalized severely demented patients identified as vocally disruptive by nurses. International Journal of Geriatric Psychiatry, 8, 155-164.

Hegel GWF. (1967). The Phenomenology of Mind. (German original, 1807). Harper \& Row, New York.

Hultén A., Kerstell J., Olsson R., and Svanborg A. (1969). A method to calculate nursing load. Scandinavian Journal of Rehabilitation Medicine, $1,117-125$.

Husserl E. (1976). Ideas. General Introduction to Pure Phenomenology. (German original, 1913). Humanities Press, New York.

Husserl E. (1977). Phenomenological Psychology. (German original, 1962). Martinus Nijhoff, The Hague.

Hyltenstam K. (1988). To speak Swedish as a native - or nearly. In K. Hyltenstam and I. Lindberg, Swedish as a Second Language. (Swe). The Centre for Research on Bilingualism, Stockholm University, Stockholm.

Hyltenstam K., and Stroud C. (1989). Bilingualism in Alzheimer's dementia: Two case studies. In K. Hyltenstam and L. K. Obler (Eds.) Bilingualism Across the Lifespan. Aspects of Acquisition, Maturity and Loss, Cambridge University Press, Cambridge, pp. 202-226.

Hyltenstam K., and Stroud C. (1993). Second language regression in Alzheimer's dementia. In K. Hyltenstam and $\AA$. Viberg (Eds.) Progression and Regression in Language. Cambridge University Press, Cambridge, in press.

HYKS (Helsinki Universty Central Hospital). (1991). A Method to Calculate Nursing Load in Application to Nursing Process. (Fin). Helsinki Universty Central Hospital, Helsinki.

Jaakkola M. (1983). Finnish Immigrants in Sweden: Networks and Life Styles. Research Reports. Research Group for Comparative Sociology, University of Helsinki, No 30. 
Jansson L, and Norberg A. (1992). Ethical reasoning among registered nurses experienced in dementia care. Interviews concerning the feeding of severely demented patients. Scandinavian Journal of Caring Sciences, 6, 219-227.

Jansson L., Norberg A., Sandman P-O., Athlin E., and Asplund K. (1993). Interpreting facial expressions in patients in the terminal stage of the Alzheimer disease. Omega, 26, 319-334.

Johansson E. (1987). Registration of longitudinal data by means of musical notation. Quality, multidimensionality, time: Description of a method. Quality and Quantity, 21, 59-69.

Johansson E. (1991). High precision registration of complicated longitudinal and cross-sectional data. Quality and Quantity, 25, 321-326.

Katz S., and Akpom CA. (1976). A measure of primary sociobiological functions. International Journal of Health Services, 6, 493-507.

Kempton W. (1980). The rhythmic basis of interactional microsynchrony. In M. Ritchie Key (Ed.) The Relationship of Verbal and Nonverbal Communication, Mounton Publishers New York, pp. 67-75.

Kihlgren M. (1992). Integrity Promoting Care of Demented Patients. Umeå University Medical Dissertations, New Series No 351, Umeå.

Kihlgren M., Hallgren A., Norberg A., and Karlsson I. (1993a). Disclosure of basic strengths and basic weakness in demented patients during morning care before and after staff training in integrity promoting care. Analysis of video-recordings by means of the Erikson theory of "eight stages of man". International Journal of Aging and Human Development, accepted for publication.

Kihlgren M., Hallgren A., Norberg A., and Karlsson I. (1993b). Integrity promoting care of demented patients. Patterns of interaction during morning care. International Journal of Aging and Human Development, accepted for publication.

Klemm DE. (1983). The Hermeneutical Theory of Paul Ricoeur. A Constructive Analysis. Lewisburg, Buchnell University Press, London. 
Koivukangas O. (1980). Migration from Finland to Sweden of all Time. (Swe/Fin). (Ed.) Migration Institute, Turku, Finland.

Kurucz J., and Feldmar G. (1979). Prosopo-affective agnosia as a symptom of cerebral organic disease. Journal of the American Geriatrics Society, 27, 225-230.

Laaksonen R., Erkinjuntti T., Granberg M., Amberla K., and Sulkava R. (1985). D-test battery: a comprehensive neuropsychological screening test. Preliminary results. Reports on Psychiatry Fennica, 63, 87-94.

Kuuppelomäki M., and Lauri S. (1991). The ethical decision making of nurses associated with the feeding of demented patients and terminally ill elderly cancer patients in seven countries. (Fin). Hoitotiede, 3, 146-153.

Leino-Kilpi H. (1990). Good Nursing Care. On What Basis? Annales Universitatis Turkuensis, D 49. Turku University, Turku.

Lewis HP., and Livson N. (1980). Cognitive development, personality and drawing: Their interrelationships in a replicated longitudinal study. Studies in Art Education, 22, 8-11.

Lewis TJ., and Jungman RE. (1986). On Being Foreign. Culture Shock in Short Fiction, Intercultural Press, Yarmouth, Maine, pp. xvii-xxv.

Liukkonen A. (1990). Basic Nursing Care of Demented Patients Living in Institutions. Annales Universitatis Turkuensis, C 81, Turku University, Turku.

Majava A. (1981). Finns in Sweden: Characteristics and living conditions. In M. Karni (Ed.) Finnish Diaspora I: Canada, South America, Africa, Australia and Sweden. The Multicultural History Society of Ontario, Toronto.

Markides KS., and Mindel CH. (1987). Aging \& Ethnicity. Sage Library of Social Research, 163, Sage Publications, New York.

Mayeroff M. (1965). On caring. The International Philosophical Quarterly, 5, 462-474. 
McKhann G., Drachman D., Folstein M., Katzmann R., Price D., and Stadlan EM. (1984). Clinical diagnosis of Alzheimer's disease. Neurology, 34, 939-944.

Meisel J. (1989). Early differentiation of language in bilingual children. In K. Hyltenstam and L. K. Obler (Eds.) Bilingualism Across the Lifespan. Aspects of Acquisition, Maturity and Loss. Cambridge University Press, Cambridge, pp. 13-40.

Melges FT. (1982). Time and the Inner Future. A Temporal Approach to Psychiatric Disorders. John Wiley \& Sons, New York.

Merleau-Ponty M. (1973). Consciousness and the Acquisition of Language. (French original, 1964). Northwestern University Press, Evanston.

Merleau-Ponty M. (1974). Phenomenology of Perception. (French original, 1945). Humanities Press, New York.

Miller E. (1989). Language impairment in Alzheimer type of dementia. Clinical Psychology Review, 9, 181-195.

Montgomery SA., and Åsberg M. (1979). A new depression scale designed to be sensitive to changes. British Journal of Psychiatry, 134, 382-389.

National Board of Health and Welfare and Swedish Immigrant Board (1991). Multicultural Care for Elderly. (Swe). National Board of Health and Welfare, Stockholm.

Nilstun T. (1992). Theory and methods for research on ethical issues in dementia care. Scandinavian Journal of Caring Sciences, 6, 173-177.

Norberg A., Axelsson K., Hallberg IR., Lundman B., Athlin E., Ekman S-L., Engström B., Jansson L., and Kihlgren M. (1992). The Mosaic of Care. A Model. (Swe). Almqvist \& Wiksell, Stockholm.

Norberg A., and Asplund K. (1990). Caregivers' experience of meaning in caring for severely demented patients in the terminal phase of life. Western Journal of Nursing Research, 12, 75-84. 
Norberg A., and Hirschfeld M. (1987). Feeding of severely demented patients in institutions. Interviews with caregivers in Israel. Journal of Advanced Nursing, 12, 551-557.

Norberg A., Melin E., and Asplund K. (1986). Reactions to music, touch and object presentation in the final stage of dementia. An exploratory study. International Journal of Nursing Studies, 23, 315-323.

Norberg A., and Sandman PO. (1988). Existential dimensions of eating in Alzheimer patients. An analysis by means of EH. Erikson's theory of 'eight stages of man'. Recent Advances in Nursing, 21, 127-134.

Norberg A., Sandman P-O., and Winblad B. (1985). Ethical reasoning in dementia research. (Swe). Läkartidningen, 82, 4528-4530.

Norberg A., and Asplund K. (1990). Caregivers' experience of meaning in caring for severely demented patients in the terminal phase of life. Western Journal of Nursing Research, 12, 75-84.

Obler LK., and Albert M. (1984). Language in aging. In M. Albert (Ed.) Clinical Neurology of Aging. Oxford University Press, New York.

Paterson JG., and Zderad LT. (1988). Humanistic Nursing. 2nd ed. (1st ed. 1976), National League for Nursing, New York.

Poplack S. (1980). Sometimes I'll start a sentence in Spanish y termino en Espanol: Towards a typology of code-switching. Linguistics, 18, 581-618.

Rapcsak SZ., Croswell SC., and Rubens AB. (1989). Apraxia in Alzheimer's disease. Neurology, 39, 664-668.

Reisberg B. (1983). The Brief Cognitive Rating Scale and Global Deterioration Scale. In T. Crook, S. Ferris, and R. Bartus (Eds.) Assessment in Geriatric Psychopharmacology. Mark Powley Associates, Connecticut.

Reisberg B. (1986). Dementia: A systematic approach to identifying reversible causes. Geriatrics, 41, 30-46. 
Reisberg B., Ferris SH., Klunger A., Franssen E., De Leon MJ., Mittelman M., Borenstein J., Rameshwar K., and Alba R. (1989). Symptomatic changes in CNS aging and dementia of the Alzheimer type: Cross-sectional, temporal, and remediable concomitants. In M. Bergener and B. Reisberg (Eds.) Diagnosis and Treatment of Senile Dementia. Springler Verlag, Berlin, pp. 193-223.

Reitan RM. (1958). Validity of the trail making test as an indication of organic brain damage. Perceptual and Motor Skills, 8, 271-276.

Ricoeur P. (1970). Freud and Philosophy: An Essay on Interpretation. (French original, 1965). Yale University Press, New Haven.

Ricoeur R. (1971). The model of the text: Meaningful action considered as a text. Social Research, 38, 529-562.

Ricoeur P. (1976). Interpretation Theory: Discourse and the Surplus of Meaning. Christian University Press, Fort Worth, Texas.

Ringler NM. (1983). From prespeech to language: The influence of caregiver-child interaction. Infant Mental Health Journal, 1, 43-50.

Sandman P-O., Norberg A., Adolfsson R., Eriksson S., and Nyström L. (1990). Prevalence and characteristics of persons with dependency on feeding at institutions for elderly. Scandinavian Journal of Caring Sciences, 4, 121-127.

Sandman PO, Adolfsson R, Norberg A, Nyström L, and Winblad B. (1988). The long-term care of the elderly. A descriptive study of 3600 patients in different institutions in the county of Västerbotten, Sweden. Comprehensive Gerontology A, 2, 120-133.

Satir V. (1976). Making Contact. Celestial Arts, Millbrae, California.

Schierup C-U. (1987). Do They Dance to Keep up Tradition? Immigrants, Culture and Society. Doctoral Dissertation, Department of Sociology, Umeå University, Umeå.

Slesinski R. (1984). Pavel Florensky; A Metaphysics of Love. St. Vladimir Seminary Press, New York. 
Stern DN. (1990). Diary of a Baby. What the Child Sees, Feels, and Experiences. Basic Books, New York.

Watzlawick P., Bavelas JB., and Jackson DD. (1967). Pragmatics of Human Communication. A Study of Interactional Patterns, Pathologies and Paradoxes. WW. Norton \& Company, New York, pp. 48-51.

Wechsler D. (1981). Wechsler Adult Intelligence Scale. Revised. The Psychological Corporation, Harcourt Brace Jovanowich, San Antonio, Texas.

Wilkinson L. (1989). SYSTAT, The System for Statistics. Evanston, Il, pp. 61-67.

Zingmark K., Norberg A., and Sandman P-O. (1993). Experience of athomeness and homesickness in patients with Alzheimer's disease. American Journal of Alzheimer's Care and Related Disorders \& Research, accepted for publication.

Åkerlund BM., and Norberg A. (1985). An ethical analysis of double bind conflicts as experienced by care workers feeding severely demented patients. International Journal of Nursing Studies, 2, 207-216.

Åkerlund BM., and Norberg A. (1990). Powerlessness in terminal care of demented patients: an exploratory study. Omega, 21, 15-19.

Allund A. (1978). Migration and the Process of Social Change: The Case of the Contemporary Yugoslav Emigrants. Research Report No 44, Department of Sociology, Umeå University, Umeå.

Ålund A. (1985). Walls of Protection. Ethnicity and Class among Immigrants. (Swe). Liber, Stockholm. 
